\title{
CLEAR LENS EXTRACTION VERSUS PHAKIC IOL IMPLANTATION: A PROSPECTIVE STUDY OF TWO PROCEDURES IN PATIENTS WITH HIGH MYOPIA
}

\author{
Alsmman, A. ${ }^{(*)}$, Abdellah, M., Abdelatif, I. \& Ismail, A. \\ Ophthalmology dept., Faculty of Medicine, Sohag Univ., Sohag, Egypt \\ ${ }^{(*)}$ E-mail: alahmady20@yahoo.com
}

\begin{abstract}
Purpose: To compare clear lens extraction (CLE) and phakic intraocular lens posterior chamber intraocular (PIOL) lens implantation (Artisanintraocular lens (IOL) \& Implantable Collamer Lens (ICL) for correction of high myopic patients younger than 40 years. Methods: A prospective nonrandomized study included 64 eyes (45 highly myopic patients) divided into three groups: Group $A$; received CLE and IOL implantation, Group B; received Artisan PIOL, and Group C; received ICL PIOL. All cases were evaluated on the $1^{\text {st }}$ day, $1^{\text {st }}$ week, $1^{\text {st }}$ month, $6^{\text {th }}$ month, $12^{\text {th }}$ month, and $18^{\text {th }}$ month postoperatively. The evaluation included assessment of visual acuity, IOP, refraction, IOL stability \& search for postoperative complications. Results: The postoperative efficacy index after 1 month was (101.7\%, 98.6\% \& 98.8\%) and after 18 months (100.3\%, 98.6\% \& 98.15\%) for groups $A$, $B \& C$ respectively. While the postoperative spherical equivalent refraction at 18 months was variable. Group $A$ included 17 eyes within $1.0 \mathrm{D}$ and 9 eyes within $0.5 \mathrm{D}$. While group $B$ included 18 eyes within $1.0 \mathrm{D}$ and 11 eyes within $0.5 \mathrm{D}$, and group $C$ included 22 eyes within $1.0 \mathrm{D}$ and 11 eyes within $0.5 \mathrm{D}$. Conclusions: There was no difference between clear lens extraction and phakic IOL implantation as a management of high myopia.
\end{abstract}

Keywords: Clear lens extraction, Phakic Artisan IOL \& Phakic ICL

\section{Introduction}

The refractive state of the eye depends on the shape of the cornea, the power of the lens and the length of the eye. Four major types of naturally occurring refractive errors have been described: myopia, hyperopia, astigmatism, and presbyopia. In myopia, the refractive power of the eye is greater than that required for emmetropia. So, parallel rays of light entering the eye are in focus at a location in the vitreous rather than on the retina [1].
Correction of high myopia has always been a challenge owing to the unavailability of a satisfactory surgical procedure. Surgical techniques based on the modification of the corneal curvature, like laser-assisted in situ keratomileusis (LASIK), Photo refractive keratectomy (PRK), and laser assisted epithelial keratomileusis (LASEK), used to be very popular. However, the complications associated with these techniques have justified the search for new 
techniques with better outcomes [2]. The recent advances in technology have paid more respect to the cornea, allowing for preservation of its normal curvature. The intraocular procedures which are based on lens extraction with or without implantation of an intraocular lens (IOL)

\section{Patients and Methods}

This prospective, comparative non randomized study included 64 eyes of 45 high myopic patients presented to the Ophthalmology department at Sohag University Hospital in the period between January 2012 and October 2014. Patients were divided into three groups (A, B, \& C) depending on the patient's choice of the surgical technique, after explaining all available techniques. However, contraindications of each technique were considered, and the contraindicated technique was not offered to the patient. As in cases with anterior chamber depth (ACD) less than $2.88 \mathrm{~mm}$. Where Phakic IOL is contraindicated. Group A, included 19 eyes of 14 patients ( 9 females and 5 males) with age range of (24-40) years, were subjected to clear lens extraction with foldable posterior chamber intraocular lens (Acrysof, Alcon). Two models were used; Acrysof MA60AC and Acrysof SA60AT. Group B, included 22 eyes of 15 patients ( 8 females and 7 males) with age range of (20-38) years, were subjected to anterior chamber phakic IOL (Artisan). Lastly, group C included 23 eyes of 16 patients ( 9 females and 7 males) with age range of (21-37) years, were subjected to posterior chamber phakic IOL (ICL); ICM V4. All included cases were 18-40 years; they were highly myopic ( $\geq-8 \mathrm{D})$ and unfitted for the corneal refractive surgeries. All cases were

\section{Surgical Technique}

\subsection{Clear lens extraction}

Preoperatively, patients were prepared as for a standard cataract surgery, under local anesthesia a $2.2 \mathrm{~mm}$ primary incision was made at 12 o'clock (for inserting the lens) and two paracenteses through anterior capsulorhexis were made and phakic IOL implantation preserve the corneal structure, hence, their current popularity [3]. This study compared the use of CLE and phakic IOL implantation (Artisan IOL \& ICL) for correction of high myopic patients younger than 40 years.

subjected to a thorough preoperative examination to exclude other eye pathologies as maculopathy, cataract, uveitis, retinal holes or tears, and glaucoma. Cases with a suspicious macula were subjected to further assessment using the Fluorescein angiography, and only negative cases were included in this study. The examination included anterior segment examination using slit lamp, IOP measurement by applanation tonometry, full retinal examination, and indirect ophthalmoscopy and panfandoscopic lens. All cases were free except for two cases were diagnosed with peripheral retinal tears and managed using retinal argon laser photocoagulation. The manifest and the cycloplegic refraction were recorded, and the UCVA and the BCVA were recorded for all cases. Scheimpflug imaging was used to evaluate the anterior chamber depth, corneal $\mathrm{k}$ reading, and the white to white diameter. Furthermore, the White to white (W-t-W) diameter was reevaluated man-ually by a caliber [4]. Before the surgery, patients were given detailed explanations of the possible implications and the surgical technique. All patients signed a written consent form in accordance with the Helsinki Declaration. The ethical committee of Sohag University. approved this study protocol.

at 10 and 2 o'clock (for instrument access to fixate the lens). Then hydrodissection of the lens followed by irrigation/ aspiration of the soft nucleus in 15 cases, and phacoemulsification of the harder nucleus in 4 cases. After removal 
of the cortex, a careful polishing of the posterior capsule was done, and a foldable (acrysof) IOL of a low positive or minus power was implanted into the capsular bag. Instillation of a cohesive viscoelastic material through the paracenteses and primary incision was mandatory to

\subsection{Artisan IOL implantation}

Preoperatively, patients were prepared by administration of $2 \%$ pilocarpine eye drops to the eye at 15-minute intervals for 60 minutes. Under general anesthesia, two side ports were created at 10 and 2 o'clock then the viscoelastic agent (sodium hyaluronate) was injected to maintain a stable anterior chamber throughout the surgical procedure. A $5.2-\mathrm{mm}$ or $6.2 \mathrm{~mm}$ valvedlimbal incision was created between the 10 and 2 o'clock positions according to the optical diameter of the Artisan phakic IOL which is either $5 \mathrm{~mm}$ or $6 \mathrm{~mm}$ respectively followed by another injection

\subsection{ICL Implantation}

It was performed under general anesthesia. The ICL was first loaded into a cartridge using viscoelastic, methylcellulose and balanced salt solution. A 3.2 $\mathrm{mm}$ clear temporal corneal incision with a pair of $1.0-\mathrm{mm}$ paracentesis incisions at 6 o'clock \& 12 o'clock positions were done. Then the viscoelastic material was injected into the anterior chamber. The preloaded injector mechanism was brought into the operative field, and the tip of the cartridge was inserted into the clear corneal wound, the surgical plane was parallel to the iris, avoiding contact with corneal endothelium and anterior lens capsule. When $1 / 2$ to $3 / 4$ of the ICL was out of the injector cartridge, a slow unfolding of the implant started. The paracentesis incisions were used to provide access to the ICL. The leading footplates were positioned first then the ICL manipulator was inserted through the side port incision. Using gentile posterior pressure, the footplates were tucked one at a time under the iris. Once the footplates were visually confirmed to be posterior to the iris, the pupil was pharmacologically constricted using maintain sufficient $\mathrm{ACD}$, protect the endothelium, and facilitate adjusting the lens within the eye during fixation. The viscoelastic material was completely removed by manual irrigation in front of the IOL at the end of the procedure.

of the viscoelastic agent. The phakic IOL was introduced toward the 6 o'clock position and rotated to be horizontally placed. A snip of the iris was introduced gently between the lens claws on each side, and a peripheral iridectomy was performed using a surgical scissor or a vitrectomy cutter. Finally, the incision was closed using 10-0 nylon. Before the knot was tied, irrigation of the anterior chamber with a balanced salt solution was performed to remove any remaining viscoelastic material.

Miochol (Novartis, Cambridge, Mass). A peripheral iridectomy was done using a vitreous cutter followed by irrigation of the anterior chamber with a balanced salt solution using a 27-gauge cannula through the wound. In the end, the clear corneal incision was sealed by stromal hydration, and an eye patch was applied for the following 6-12 hours. A postoperative evaluation of the visual acuity, Intra ocular pressure IOP, refraction, stability of the IOL was performed for all cases to detect any complications on day one and week one postoperatively, then after one month, six months, twelve months, and eighteen months. Patients were advised to contact us and request an extra visit if any possible complication was suspected. The most commonly detected complications include posterior capsule opacification (PCO), choroidal neovascularization ( $\mathrm{CNV})$, and postoperative reading difficulty for the CLE group, pigment dispersion, anterior uveitis, and induced astigmatism for the Artisan group, elevated IOP and cataract for the ICL group. 


\section{Statistical Analysis}

The results were analyzed using the Independent student's t-test, the paired t-test, and the ANOVA test. A Pvalue $<0.05$ was used as significance determinate. The data were analyzed using SPSS for Windows version 19.0 software (SPSS Inc., Chicago, IL, USA) and shown as a comparison of the mean

\section{Results}

The mean age of group A (CLE) was (35.3 \pm 3.5$)$, group B (Artisan) was (24.58 \pm 6.8 ) and group C (ICL) was $28 \pm$ 4. Group A (CLE) showed statistically significant higher results than the other two groups (P-value < 0.001), fig. (1). The mean value of the preoperative spherical equivalent refraction showed no significant difference between the $\mathrm{A}, \mathrm{B} \& \mathrm{C}$ groups $(-16.97 \pm 5.23,-14.178 \pm 2.827 \&-15.62 \pm$ 2.94 respectively) (P-value 0.071). Also, the UCVA was significantly different between the three groups $\mathrm{A}, \mathrm{B}, \& \mathrm{C}$ $(0.019 \pm 0.012, \quad 0.034 \pm 0.013 \& 0.028 \pm$ 0.012 respectively) (P-value 0.24$)$, tab. (1). The Pachymetry mean value showed an insignificant difference between the three groups. Group A was (489.56 \pm 45.4$)$, and standard deviation of the three groups. The quai-ltative data was expressed in the form of numbers and percentages and compared using the chi-square test where the P-value was considered significant if it was less than 0.05 .

group B was (473.79 \pm 41.9$)$ and group $\mathrm{C}$ was (505.53 \pm 34.662$)$ (P-value 0.065). The AC depth was lower in group A $(2.904 \pm 0.156 \mathrm{~mm})$ than in group $B$ (3.346 \pm 0.137$)$ and group $C(3.174 \pm 0.249)$ with (P-value $<0.001)$ which is statistically significant. This is attributed to that; all cases in group A had an AC depth < $2.8 \mathrm{~mm}$, tab. (1). The postoperative UCVA and the refractive outcome were considered indicators of the procedure efficacy. The refractive outcome was measured on day one and week one postoperatively, then after one month, six months, twelve months and lastly, eighteen months. The final follow-up was done one month after achieving the refractive stability.

Figure (1) the difference in age between the three groups

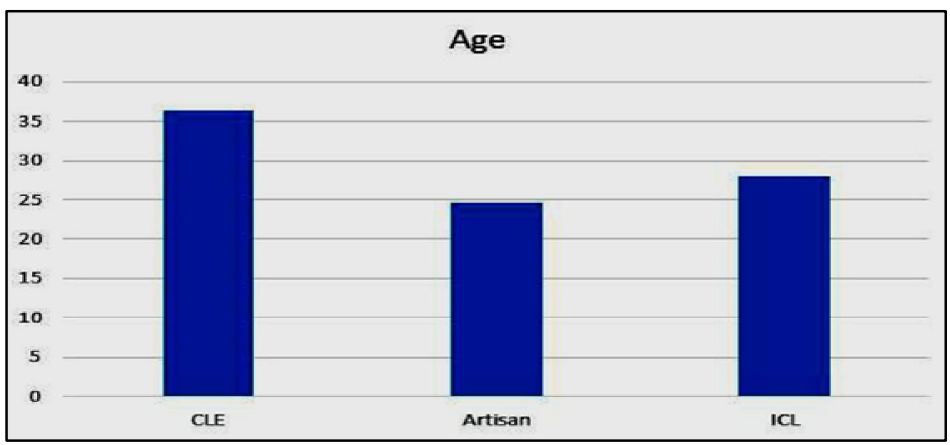

Table (1) the preoperative data in the three groups

\begin{tabular}{|c|c|c|c|c|c|c|c|c|c|}
\hline \multirow{3}{*}{$\begin{array}{c}\text { Preoperative } \\
\text { data } \\
\end{array}$} & \multicolumn{8}{|c|}{ Groups } & \multirow{3}{*}{$\begin{array}{c}\mathbf{P} \\
\text { value }\end{array}$} \\
\hline & \multicolumn{2}{|c|}{$C L E$} & \multicolumn{2}{|c|}{ Artisan } & \multicolumn{2}{|c|}{ ICL } & \multicolumn{2}{|c|}{ Total } & \\
\hline & Mean & SD & Mean & SD & Mean & SD & Mean & SD & \\
\hline Pre SphEqi & -16.972 & 5.237 & -14.178 & 2.827 & -15.618 & 2.945 & -14.886 & 4.25 & 0.071 \\
\hline UCVA & 0.019 & 0.012 & 0.034 & 0.013 & 0.028 & 0.012 & 0.027 & 0.013 & 0.121 \\
\hline BCVA & 0.322 & 0.115 & 0.432 & 0.119 & 0.434 & 0.165 & 0.397 & 0.142 & 0.24 \\
\hline Pachymetry & 489.56 & 45.404 & 473.79 & 41.915 & 505.53 & 34.662 & 489.63 & 42.183 & 0.065 \\
\hline K1 & 44.381 & 1.374 & 43.848 & 2.024 & 43.766 & 1.508 & 43.992 & 1.656 & 0.483 \\
\hline K2 & 46.133 & 2.017 & 45.006 & 1.886 & 45.338 & 1.534 & 45.481 & 1.848 & 0.165 \\
\hline WTW & 11.743 & 0.378 & 11.967 & 0.582 & 11.557 & 0.336 & 11.756 & 0.47 & 0.124 \\
\hline AC DEPTH & 2.904 & 0.156 & 3.346 & 0.137 & 3.174 & 0.249 & 3.146 & 0.259 & $<0.001$ \\
\hline
\end{tabular}

SD: Standard deviation, Pre SphEqi: preoperative spherical equivalent, UCVA: uncorrected visual acuity, BCVA: best corrected visual acuity, keratometry K1:, K2:,WTW: White to White, AC DEPTH: anterior chamber . 
In group $\mathbf{A}$, the mean spherical equivalent refraction was $-0.278 \mathrm{D} \pm 0.696$ (SD), $-0.285 \mathrm{D} \pm 0.683$ (SD), $-0.272 \mathrm{D} \pm$ 0.685 (SD), $-0.290 \mathrm{D} \pm 0.692$ (SD) \&$0.299 \mathrm{D} \pm 0.690(\mathrm{SD})$ at the $1^{\text {st }}$ week, $1^{\text {st }}$, $6^{\text {th }}, 12^{\text {th }}$ and $18^{\text {th }}$ month respectively. The spherical equivalent refraction at the last examination was within $1.0 \mathrm{D}$ of the targeted refraction in 17 eyes $(89.47 \%)$ and within $0.5 \mathrm{D}$ in 9 eyes $(47.3 \%)$, tab. (2). In group $\mathbf{B}$, the mean spherical equivalent refraction at the $1^{\text {st }}$ week was $-0.498 \pm 0.875(\mathrm{SD})$, at the $1^{\text {st }}$ month was $-0.507 \pm 0.882(\mathrm{SD})$, at the $6^{\text {th }}$ month was $-0.512 \mathrm{D} \pm 0.785$ (SD), at the $12^{\text {th }}$ month was $-0.513 \mathrm{D} \pm 0.692(\mathrm{SD})$, and at the $18^{\text {th }}$ month, the mean spherical equivalent refraction was $-0.544 \mathrm{D} \pm 0.701$ (SD). The spherical equivalent refraction at the last examination was within $1.0 \mathrm{D}$ of the targeted refraction in 18 eyes $(81.8 \%)$ and within $0.5 \mathrm{D}$ in 11 eyes (50\%), tab. (2). In group $\mathbf{C}$ the mean spherical equivalent refraction at the $1^{\text {st }}$ week, 1 st month, $6^{\text {th }}$ month was $-0.099 \mathrm{D} \pm 0.839$ (SD), -0.099 $\mathrm{D} \pm 0.839$ (SD), $-0.112 \mathrm{D} \pm 0.79$ (SD) respectively. At the $12^{\text {th }}$ month was -0.22 $\mathrm{D} \pm 0.78$ then it became $-0.23 \mathrm{D} \pm 0.801$ (SD) at the $18^{\text {th }}$ month. The spherical equivalent refraction at the last examination was within $1.0 \mathrm{D}$ of the targeted refraction in 22 eyes $(91.3 \%)$ and within $0.5 \mathrm{D}$ in 11 eyes $(47.8 \%)$, tab. (2).

Table (2) the refractive outcome in the three groups.

\begin{tabular}{|c|c|c|c|}
\hline The refractive outcome & Group A & Group B & Group C \\
\hline $1^{\text {st }}$ week & $-0.278 \mathrm{D} \pm 0.696$ & $-0.498 \pm 0.875$ & $-\mathbf{0 . 0 9 9} D \pm 0.839$ \\
\hline $\mathbf{1}^{\text {st }}$ month & $-0.285 \mathrm{D} \pm 0.683$ & $-0.507 \pm 0.882$ & $-0.099 \mathrm{D} \pm 0.839$ \\
\hline $6^{\text {th }}$ month & $-0.272 \mathrm{D} \pm 0.685$ & $-0.512 \mathrm{D} \pm 0.785$ & $-0.112 \mathrm{D} \pm 0.79$ \\
\hline $12^{\text {th }}$ month & $-0.290 \mathrm{D} \pm 0.692$ & $-0.513 \mathrm{D} \pm 0.692$ & $-0.22 \mathrm{D} \pm 0.78$ \\
\hline $18^{\text {th }}$ month & $-0.299 \mathrm{D} \pm 0.690$ & $-0.544 \mathrm{D} \pm 0.701$ & $-0.23 \mathrm{D} \pm 0.801$ \\
\hline
\end{tabular}

D: Diopter

The IOP was routinely measured at each visit using Goldmann applanation tonometry. In group A (clear lens extraction), the mean preoperative IOP was $14.35 \pm 1.78 \mathrm{~mm} \mathrm{Hg}$ and became $13.435 \pm$ $2.28,15.7 \pm 10.9,14.16 \pm 2.5,13.54 \pm 1.988$, $13.46 \pm 1.36$ and $13.77 \pm 2.031 \mathrm{mmHg}$ at the 1 day, $1^{\text {st }}$ week, $1^{\text {st }}, 6^{\text {th }}, 12^{\text {th }}$ and $18^{\text {th }}$ month respectively with statistically insignificant differences. In group B (Artisan insertion), there were no significant changes in the IOP. The mean preoperative IOP was $13.16 \pm 1.37 \mathrm{~mm} \mathrm{Hg}$ then became $15.16 \pm 2.8$, at $1^{\text {st }}$ week, $14.2 \pm 2.43,13.52 \pm$ $2.139 \mathrm{~mm} \mathrm{Hg}$ at the $1^{\text {st }}$ month, $13.46 \pm$
$1.37 \mathrm{mmHg}$ at the $6^{\text {th }}$ month, $13.77 \pm$ $1.98 \mathrm{mmHg}$ at the $12^{\text {th }}$ month and $13.53 \pm$ $2.12 \mathrm{mmHg}$ at the $18^{\text {th }}$ month. In group C (ICL insertion), the mean preoperative IOP was $13.9 \pm 2.6$, then increased at the $1^{\text {st }}$ day postoperatively $(22.79 \pm 5.79)$ and the 1st week $(18.56 \pm 4.34 \mathrm{mmHg})$, and became $16.12 \pm 3.09,14.47 \pm 2.14$, $14.10 \pm 1.88 \& 14.05 \pm 2.17 \mathrm{mmHg}$ at the 1 , 6,12 , and 18 months respectively. Comparing the three groups, it was found that group $\mathrm{C}$ had the highest postoperative IOP at the $1^{\text {st }}$ day and the 1 st week with statistically significant results (P-value < 0.001), fig. (2).

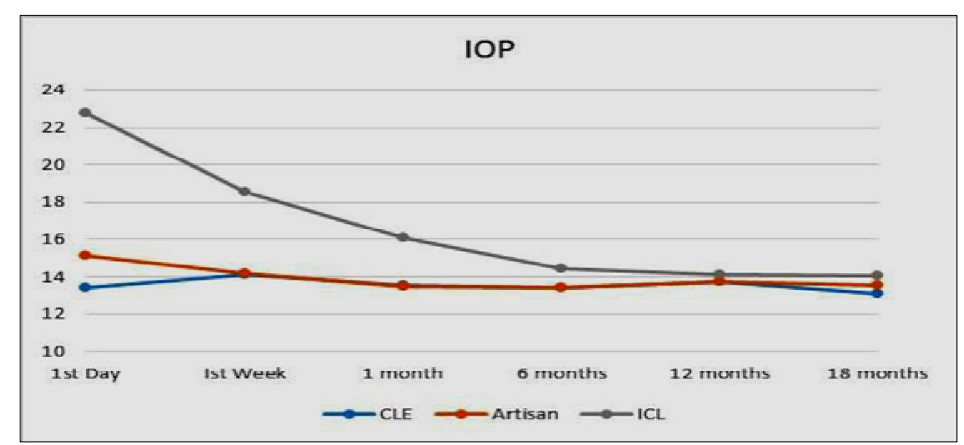

Figure (2) the change in IOP during the postoperative period in the three groups 
In group $\mathbf{A}$ (CLE), the preoperative best corrected visual acuity (BCVA) in $89.4 \%$ was $>0.2 .26 .3 \%$ achieved $>0.4$ at the $1^{\text {st }}$ day postoperatively then $42.1 \%$ at the $1^{\text {st }}$ month, $40 \%$ at the 6th month, $36.8 \%$ at the $12^{\text {th }}$ month, and finally $31.5 \%$ at the $18^{\text {th }}$ month. In group $\mathbf{B}$ (Artisan PIOL), the preoperative best corrected visual acuity (BCVA) in $54.5 \%$ of patients was $\geq 0.4$, then in the $1^{\text {st }}$ day postoperatively the visual acuity was $\geq$ 0.2 in $90.1 \%$ of cases and $\geq 0.4$ in $31.8 \%$, which then increased to $\geq 0.4$ in $45.4 \%$ of cases. A visual acuity of $\geq 0.4$ was detected in $63.6 \%$ of cases at the $1^{\text {st }}$ month postoperatively, and $63.6 \%$ at the $6^{\text {th }}$ month, then $59 \%$ at the $12^{\text {th }}$ month, and lastly $59 \%$ at the $18^{\text {th }}$ month. In group C (ICL PIOL), the preoperative best corrected visual acuity (BCVA) was $\geq$ 0.4 in $47.8 \%$. Postoperatively in the $1^{\text {st }}$ day, the visual acuity was $\geq 0.2$ in $91.3 \%$ of cases and $\geq 0.4$ in $30.4 \%$, then became $\geq 0.4$ in $43.4 \%$ of cases at the $1^{\text {st }}$ week, $56.5 \%$ at the 1 st month, $52.1 \%$ at the 6th month, $52.1 \%$ at the $12^{\text {th }}$ month, and $47.8 \%$ at the $18^{\text {th }}$ month. The difference in the mean visual acuity of the three groups was statistically insignificant at the $1^{\text {st }}$ day, $1^{\text {st }}$ month, 6 months, 12 months and 18 months postoperatively (P-value $0.733,0.239,0.088$, $0.29,0.07, \& 0.121$ respectively), fig. (3).

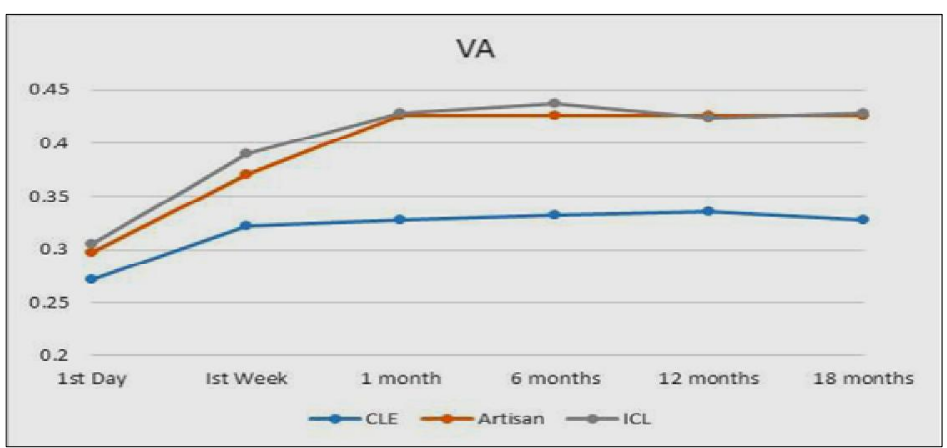

Figure (3) the postoperative VA change in the three groups

The efficacy index (the mean postoperative UCVA / the mean preoperative BCVA) was calculated at the $1^{\text {st }}$ and $18^{\text {th }}$ month postoperatively. At the $1^{\text {st }}$ month, it was $(101.7 \%)$ in group $\mathbf{A},(98.6 \%)$ in group B, and (98.8\%) in group C, tab. (3). At the $18^{\text {th }}$ month, group A was $(100.3 \%)$, group B was (98.6\%), and group C was $(98.15 \%)$ as shown in tab. (4).

Table (3) the efficacy index and the difference between the preoperative BCVA \& postoperative UCVA after 1 month.

\begin{tabular}{|c|c|c|c|}
\hline & $\begin{array}{l}\text { Group A } \\
\text { (CLE) }\end{array}$ & $\begin{array}{l}\text { Group B } \\
\text { (Artisan) }\end{array}$ & $\begin{array}{l}\text { Group C } \\
\text { (ICL) }\end{array}$ \\
\hline Preoperative BCVA & $0.322 \pm 0.115$ & $0.432 \pm 0.119$ & $0.434 \pm 0.165$ \\
\hline Postoperative UCVA at the $1^{\text {st }}$ month & $0.326 \pm 0.102$ & $0.426 \pm 0.113$ & $0.429 \pm 0.155$ \\
\hline P value & 0.832 & 0.607 & 0.846 \\
\hline $\begin{array}{l}\text { Efficacy index= Postoperative UCVA / preoperative } \\
\text { BCVA }\end{array}$ & $101.7 \%$ & $98.6 \%$ & $98.8 \%$ \\
\hline
\end{tabular}

UCVA: uncorrected visual acuity, BCVA: best corrected visual acuity

Table (4) the efficacy index and the difference between the preoperative BCVA \& postoperative UCVA after 18 months

\begin{tabular}{|c|c|c|c|}
\hline & $\begin{array}{c}\text { Group A } \\
\text { (CLE) }\end{array}$ & $\begin{array}{l}\text { Group B } \\
\text { (Artisan) }\end{array}$ & $\begin{array}{c}\text { Group C } \\
\text { (ICL) }\end{array}$ \\
\hline BCVA & $0.322 \pm 0.115$ & $0.432 \pm 0.119$ & $0.434 \pm 0.165$ \\
\hline Postop UCVA at the $18^{\text {th }}$ month & $0.328 \pm 0.10$ & $0.426 \pm 0.113$ & $0.429 \pm 0.144$ \\
\hline$P$ value & 0.829 & 0.607 & 0.846 \\
\hline Efficacy index= Postop UCVA / preoperative BCVA & $100.3 \%$ & $98.6 \%$ & $98.15 \%$ \\
\hline
\end{tabular}

UCVA: uncorrected visual acuity, BCVA: best corrected visual acuity 
In group A (CLE), two cases (10.5\%) developed posterior capsular opacification (PCO) treated by YAG posterior capsulotomy, one case $(5 \%)$ developed myopic choroidal neovascularization $(\mathrm{CNV})$ at the $16^{\text {th }}$ month postoperatively treated by intravitreal anti-VEGF injection and Lucentis (Ranibizumab) $0.05 \mathrm{ml}$ once per month for 3 months, 7 cases out of 14 patients (50\%) experienced near sight reading and near sight working difficulty managed by fitting of reading glasses. Also, one case (5.2\%) developed acute PVD 10 months postoperatively. Fortunately, there were no reported cases of retinal detachment or endophthalmitis during the follow-up period. In group B (Artisan PIOL), pigment dispersion and deposition on the IOL occurred in 3 cases (13.6\%) as shown in fig. (4). One case (4.5\%) developed postoperative high astigmatism (cylindrical -4D) caused by the stitch effect and decreased to $-1.25 \mathrm{D}$ after removal of the stitch. Acute anterior uveitis occurred in one female patient $(4.5 \%)$ at the $17^{\text {th }}$ day postoperatively with dropped V/A to 0.016 , fig. (5). The patient was treated with topical and systemic prednisolone 60 mg per day in divided doses for 1 week

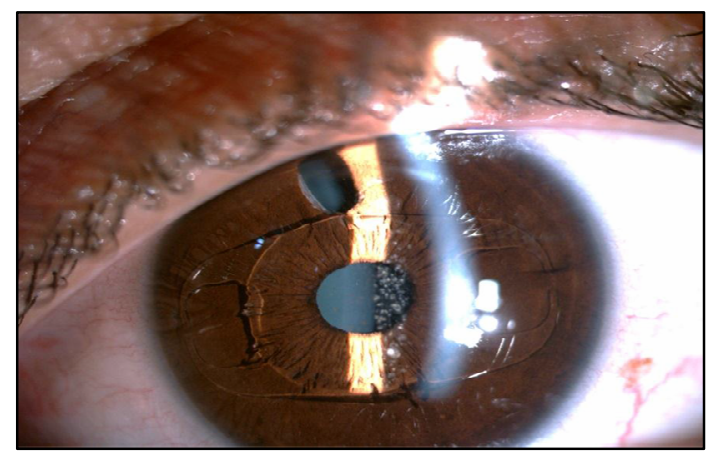

Figure (4) pigment deposition on the Artisan IOL.

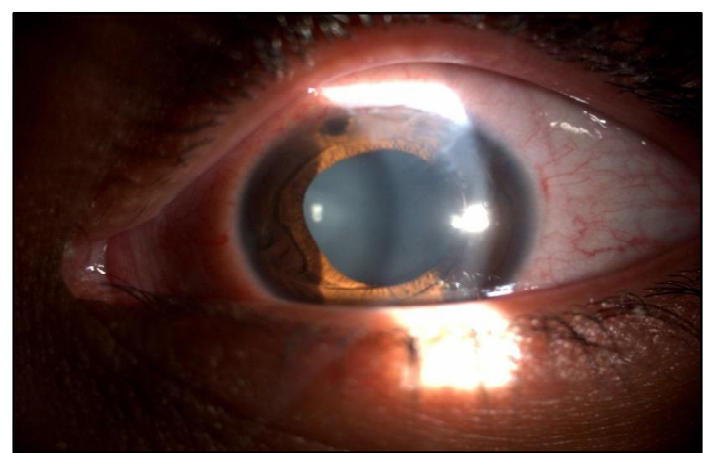

Figure (6) complete improvement after topical and systemic steroid therapy. which was then tapered over a 2 weeks period. Her V/A improved to 0.51 week later with no recurrence of the anterior uveitis during the follow-up period, fig. (6). Two cases $(9 \%)$ complained of glare during the $1^{\text {st }}$ week postoperatively, mostly due to small optic size $(5 \mathrm{~mm})$ which improved markedly after 6 months. No cases of retinal detachment or endophthalmitis cataract or increased IOP were reported. In group $\mathbf{C}$, (implantable contact lens PIOL) shallow anterior chamber in the $1^{\text {st }}$ day postoperatively occurred in $21 \%$ of cases, 4 cases $(17.3 \%)$ developed increased IOP $>21 \mathrm{mmHg}$ in the $1^{\text {st }}$ day postoperatively, the IOP decreased after 2 weeks with topical treatment in 3 cases, while the remaining case improved after 3 months with the use of combination of topical anti-glaucoma medicine (Timolol $\&$ Dorzolamide), one case ( $4.3 \%$ of cases) developed anterior sub-capsular cataract which started to significantly affect the visual acuity (dropped from 0.4 to 0.2 ) after 1 year, fig. (7). Lastly, one case $(4.3 \%)$ complained of glare in the $1^{\text {st }}$ week postoperatively which improved markedly later on.

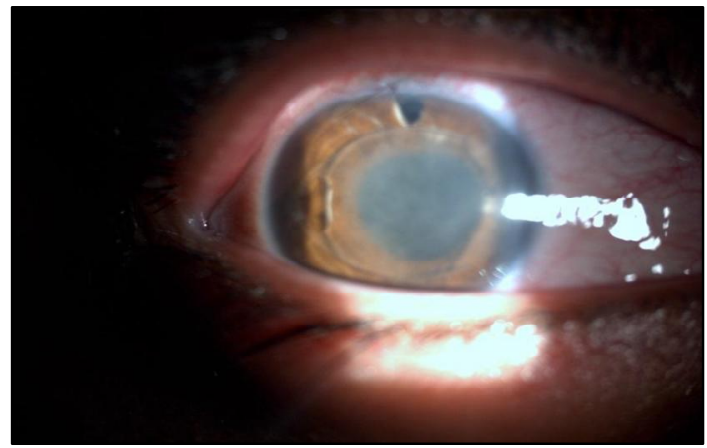

Figure (5) acute iridocyclitis with Aquos cells and fibrin membrane on the artisan IOL

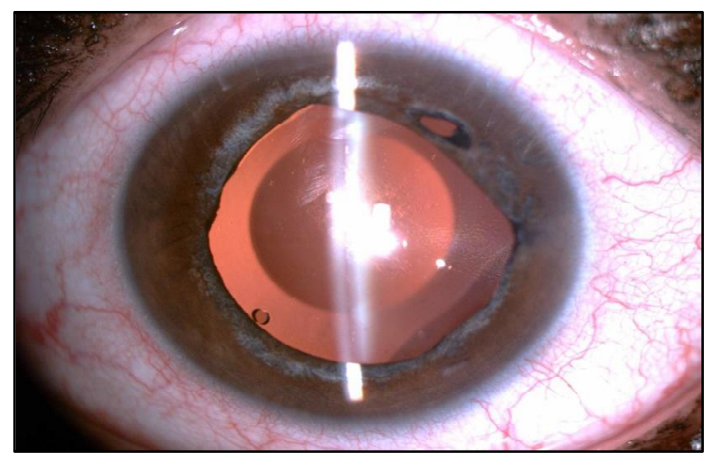

Figure (7) an anterior subcapsular cataract in ICL and Retroillumination of the same case. 


\section{Discussion}

Patients with high myopia usually prefer to get rid of the glasses and the contact lens usage, so, they seek surgical correction of the refractive error at any cost. Regarding our study, the mean age of group A was significantly higher than the other two groups to avoid loss of accommodation at a young age. While the use of phakic IOLs was minimized for the elderly to avoid early presbyopia. Our finding agreed with Jean's study by [5], Which reported a significant difference between the mean age in the ICL group (35.7 years) and the CLE group (44.6 years) (P-value $<0.05$ ). Also, the mean age was 45.5 years in W. Andrew's study [6] and Emarah et al.'s study [7], both reported a significantly higher age mean in the CLE group (36.04) than the ICL group (29.26). In our study, there were no significant differences in age between the Artisan and the ICL group, the same was found in the study of Hassaballa [8] who followed the same protocol of accommodation preservation for the younger patients. The spherical equivalent refraction at the last examination was within $1.0 \mathrm{D}$ of the targeted refraction in 17 eyes and 0.5 $\mathrm{D}$ in 9 eyes of group $\mathrm{A}$. The same results were reported by W. Andrew et al. [6]. They reported a postoperative refraction within $1.00 \mathrm{D}$ of emmetropia in $68 \%$ of eyes and within $2.00 \mathrm{D}$ in $90 \%$ of eyes. In group $\mathrm{B}$, the spherical equivalent refraction at the last examination within $1.0 \mathrm{D}$ of the targeted refraction in 18 eyes and within $0.5 \mathrm{D}$ in 11 eyes. Compared to the study of Menezo et al. [9] which was conducted on 111 high myopic eyes and reported a final spherical equivalent refraction $-0.76 \pm$ $1.52 \mathrm{D}$ one year postoperatively. The spherical equivalent refraction at the last examination was within $1.0 \mathrm{D}$ of the targeted refraction in 22 eyes and $0.5 \mathrm{D}$ in 11 eyes of group C. In Risto et al. study [10], the mean spherical equivalent refraction was $-1.80 \mathrm{D} \pm 2.34$ (SD) at the 1st month postoperatively. At the last examination, it was within $1.0 \mathrm{D}$ of the targeted refraction in $81.6 \%$ of cases, and within $0.5 \mathrm{D}$ in $71.1 \%$ of cases. The mean postopera- tive uncorrected visual acuity and the efficacy index differences were statistically insignificant for both groups (B \& C) in the $1^{\text {st }}$ day, $1^{\text {st }}$ week, $1^{\text {st }}$ month, 6th month, $12^{\text {th }}$ month, and the $18^{\text {th }}$ month $(\mathrm{P}$-value $>0.05)$, though it was a slightly higher in group A. Hassaballa [8] reported the same results in his study. There has never been a study comparing the CLE, artisan, and ICL together. However, there are many studies comparing the ICL and the Artisan Phakic IOL as Boxer et al. [11] who compared between ICL and Artisan Phakic IOL and reported that the binocular UDVA was better in the ICL group. Another study conducted by Menezo et al. [12], reported slightly better visual results with the Artisan than with the Visian ICL group. Also, a study performed by Jean [5], compared between ICL, and CLE found that BCVA was better in the ICL PIOL group than the CLE group. On the other hand, Emarah et al. [7] reported that as regard to a fixed visual acuity, the CLE was more efficient than ICL owing to its lower financial cost and infrequent need for future interference. In our study, there were no significant changes in the postoperative IOP in the CLE and the Artisan groups during the follow-up period. While, the ICl group showed significant changes at the $1^{\text {st }}$ month postoperatively, which were mostly attributed to the presence of viscoelastic residuals or the use of a slightly larger ICL diameter than the recorded W-t-W diameter, which might have been caused by an error in the caliper measurement. That also explained the postoperative shallow AC depth and the increased vault which were reported. The improvement of the shallow AC, the increased IOP, and the increased vault were explained by the spontaneous absorption of the viscoelastic residuals and the adaptation of posterior chamber to the new implant. In 2002, Bylsma et al. [13] reported pupillary block glaucoma in the 1 st week after ICL implantation. They owed it to the impaired outflow through the trabecular meshwork caused by the presence of viscoelastic material residuals anterior 
to the phakic PC IOL. This condition is managed by aggressive ocular hypotensive therapy until the IOP was normalized. Emarah et al. [7] reported in a study, that the CLE group showed a significant reduction in the mean IOP from a preoperative value of $16.25 \pm 3.34 \mathrm{mmHg}$ to a postoperative value of $14.21 \pm 3.75 \mathrm{mmHg}$ (P-value $=0.001)$. On the other hand, the ICL group showed significant elevation of mean IOP from a preoperative value of $16.15 \pm 3.21 \mathrm{mmHg}$ to a postoperative value of $18.59 \pm 2.74 \mathrm{mmHg}(\mathrm{P}$-value $=$ 0.001). Also, Chung et al. [14] reported that the early increase of the IOP was relatively frequent and usually moderate (30 $\mathrm{mmHg}$ ) due to the incomplete removal of the viscoelastic material and the instillation of the steroid eye drops or might be due to the reduction of the angle opening distance $(41.5 \%)$ and the reduction of the trabecular-iris angle (31.8\%) [14]. As regard to the complications, one case of the CLE group developed a subfoveal choroidal neovascular membrane at the $16^{\text {th }}$ month postoperatively. It was managed by macular OCT and intr-avitral anti-VEGF. Hayashi et al. [15] and Fernandez-Vega [16] reported that the incidence of myopic CNV was higher after the lens surgery; this was caused by the photo toxicity that disturbed the central retinal balance. Also, Ruiz et al. [17] suggested that there is no clear explanation for the earlier CNV development after CLE in myopic eyes, however, the inflammatory mediators, as the free radicals or growth factors associated with the biochemical and environmental changes within the eye might be responsible. There were only two cases of the CLE group who developed posterior capsular opacification and only one case of developed acute PVD, compared to the higher incidence (40-60\%) of the PCO reported by
Andrew's [6] \& Verzella's [18] studies. There were no retinal tears detected with complete magnified fundus examination. In group B (Artisan group), 4 cases deve-loped mild diffuse pigment dispersion with no affection of the visual acuity. This did not coincide with Menezo [19] who reported a lower incidence of pigment dispersion in the Artisan group (6.57\% of 137 eyes). In our study, we reported one case of anterior uveitis at the $3^{\text {rd }}$ week postoperatively. Mohamadreza Sedaghat et al. [20] reported clinically significant uveitis in 12 out of 117 eyes included in their study. In Group C, one case developed anterior subcapsular cataract associated with nuclear cataract 6 months postoperative. Alfonso et al. [21] reported a 1.3\% of 964 eyes developed cataract after ICL implantation. There was a strong correlation between the increased patient's age, the lower vault values, lower ICL sizes, and the shallower anterior chamber depths, and the incidence of cataract. One case in Group C complained of a transient glare which improved after 2 months. In agreement with our finding, a recent study done by Hui Lim et al. [22] reported night glare after ICL implantation in $26 \%$ of the patients which was related to the small optic size of ICL. No reported case of cataract in this study as cataract formation due to the iris-claw lens is very unlikely because it is inserted over a miotic pupil without touching the crystalline lens. Until now, the reported clinically relevant cataract formation was not associated with the iris-claw lens. Perez-Santoja et al. [23] only detected a loss of lens transmittance of $1.03 \%$ after 18 months by fluorophotometry that had no influence on visual acuity. Diab et al. [24] reported streptococcus endophthalmitis after Artisan IOL implantation, but this was not a finding of our study.

\section{Conclusion}

There is no difference between clear lens extraction with foldable PCIOL, anterior chamber phakic IOL (Artisan) and posterior chamber phakic IOL (ICL) in the management of high myopia. The three procedures are effective, safe and permit a better quality of life. However, it is advisable to minimize the use of the clear lens extraction with young patients to early avoid loss of the accommodation 


\section{Competing Interests}

The authors declare that there is no conflict of interests regarding the publication of this paper. None of the authors have any financial, consultant, institutional, or other relational interests to disclose.

\section{References}

1. Glazer, L., Azar, D., Refractive errors and their treatment. In: Azar, D. \& Koch, D. LASIK (Laser in Situ Keratomileusis): Fundamentals. Surgical Techniques and Complications, Marcel Dekker, Inc., NY, 2002; 26: 1-16.

2. Werblin, T., Why refractive surgeons should be looking beyond the cornea. Journal of Refractive Surgery 1999; 15 (3): 359-376.

3. Sarver, E., Sanders, D., Vukich, J., Image quality in myopic eyes corrected with laser in situ keratomileusis and phakic intraocular lens. Journal of Refractive Surgery 2003; 19 (4): 397-404.

4. Twa, M., Hurst, T., Walker, J., Waring G., Schanzlin, D., Diurnal stability of refraction after implantation with intracorneal ring segments, Journal of Cataract \& Refractive Surgery 2000; 26 (4): 516-523.

5. Arne, J., Phakic intraocular lens implantation versus clear lens extraction in highly myopic eyes of 30- to 50- yearold patients. Journal of Cataract \& Refractive Surgery 2004; 30 (10): 2092-2096.

6. Andrew Lyle, W., George Jin, J., Clear lens extraction for the correction of high refractive error. Journal of Cataract \& Refractive Surgery 1994; 20 (3): 273276.

7. Emarah, A., El-Helw, M., Yassin, H., Comparison of clear lens extraction and collamer lens implantation in high myopia. Clinical Ophthalmology (Auckland, NZ) 2010; 4: 447.

8. Hassaballa, M., Macky, T., Phakic intraocular lenses outcomes and complications, Artisan vs Visian ICL. Eye 2011; 25 (10): 1365-1370.

9. Menezo, J., Cisneros, A. RodriguezSalvador, V., Endothelial study of iris- claw phakic lens: four-year followup. Journal of Cataract \& Refractive Surgery 1998; 24 (8): 1039-1049.

10. Uusitalo, R., Aine, E., Sen, N., Laatikainen, L., Implantable contact lens for high myopia. Journal of Cataract \& Refractive Surgery 2002; 28 (1): 29-36.

11. Wachler, B., Scruggs, R., Yuen, L., Jalali, S., Comparison of the Visian ICL and Verisyse phakic intraocular lenses for myopia from 6.00 to 20.00 diopters. Journal of Refractive Surgery 2009; 25 (9): 765-770,.

12. Menezo, J., Peris-Martı'nez, C., Cisneros-Lanuza, A., Martínez-Costa, R., Rate of cataract formation in 343 highly myopic eyes after implantation of three types of phakic intraocular lenses. Journal of Refractive Surgery 2004; 20 (4): 317-324.

13. Bylsma, Stephen, S., Alan, H., Foley, E., Osher R., Phakic posterior chamber intraocular lens pupillary block. Journal of Cataract \& Refractive Surgery 2002; 28 (12): 2222-2228.

14. Chung, T., Park, S., Lee, M., Ahn, K. Chung, E., Changes in iridocorneal angle structure and trabecular pigmentation with STAAR implantable collamer lens during 2 years, Journal of Refractive Surgery 2009; 25 (3): 251-258.

15. Hayashi, K., Ohno-Matsui, K., Futagami, S., Ohno, S., Tokoro, T., Mochizuki, M., Choroidal neovascularization in highly myopic eyes after cataract extraction. Japanese Journal of Ophthalmology 2006; 50 (4): 345-348.

16. Fernandez-Vega, L., Alfonso, J. Villacampa, T., Clear lens extraction for the correction of high myopia. Ophthalmology 2003; 110 (12): 2349-2354. 
17. Ruiz-Moreno, J., Alio, J., Shabayek, M., Rosen, E., Cochener, B., Arne, J., Complications of refractive lens exchange. In: Management of Complications in Refractive Surgery. $1^{\text {st }}$ edition, Springer-Verlag NY, LLC 2008; 265-238.

18. Verzella, F., Refractive microsurgery of the lens in high myopia. Journal of Refractive Surgery 1990; 6 (4): 273-275.

19. Menezo, J., Peris-Martínez, C., Cisneros, A., Martínez-Costa, R. Phakic intraocular lenses to correct high myopia: Adatomed, Staar, and Artisan. J. of Cataract \& Refractive Surgery 2004; 30 (1): pp. 33-44.

20. Sedaghat, M., Zarei-Ghanavati, M., Ansari-Astaneh, M., Patel, V., Sikder, S., Evaluation of Sterile Uveitis after Iris-fixated Phakic Intraocular Lens Implantation, Middle East African Journal of Ophthalmology 2012; 19 (2): 199.

21. Alfonso, J., Lisa, C., Abdelhamid, A., Fernandes, P., Jorge, J., MontésMicó, R., Mon-tés-Micó R. Threeyear follow-up of subjective vault followingmyopicimplantablecollamer lens implantation. Graefe's Archive for Clinical and Experimental Ophthalmology 2010; 248 (12): 1827-1835.

22. Lim, D., Lyu, I., Choi, S., Chung, E., Chung, T., Risk Factors Associated with Night Vision Disturbances After Phakic Intraocular Lens Implantation. American Journal of Ophthalmology 2014; 157 (1): 135-141.

23. Perez-Santonja, J., Iradier, M., Benitez del Castillo, J., Serrano, J., Zato, M., Chronic subclinical inflammation in phakic eyes with intraocular lenses to correct myopia. Journal of Cataract \& Refractive Surgery 1996; 22 (2): 183-187.

24. Diab, F., Al-Rashaed, S., Al-Motowa, S., Endophthalmitis after artisan phakic intraocular lens implantation for correction of high myopia. Journal of Refractive Surgery 2006; 22 (4): 332-333. 